\title{
Cryptococcal fungemia and probable histoplasmosis in a patient infected with HIV. Case report
}

\author{
Deving Arias Ramos ${ }^{1,5^{*}} \mathbb{D}$, John Alexander Alzate ${ }^{2,5} \mathbb{D}$, Jhon Alejandro Rico Gallego ${ }^{3}$ and Natalia Acevedo Escalante ${ }^{4}$
}

\begin{abstract}
Background: Those infected by human immunodeficiency virus (HIV) have a higher risk of opportunistic infections. The risk is related to the level of immunosuppression. We report a case of a young male with the unusual scenario of three opportunistic infections occurring simultaneously: Cryptococcosis, Histoplasmosis and Cryptosporidiosis. Histoplasmosis and cryptococcosis are major causes of morbimortality in immunocompromised patients due to HIV infection.

Case presentation: We report the case of a patient with HIV infection with a CD4 T lymphocyte cell (CD4) count of 2 cells/mm3, who presented with 6 months of diarrhea, non-productive dry cough, nocturnal diaphoresis, fever, weight loss, and a maculopapular rash. He had a concurrent infection with three opportunistic microorganisms: fungemia by cryptococcosis, disseminated histoplasmosis confirmed by detection of the antigen in urine and chronic diarrhea by cryptosporidiosis confirmed by direct observation in feces by modified Ziehl-Neelsen stain. The patient received antifungal treatment with a satisfactory outcome.

Conclusions: There are still regions where HIV detection programs are deficient thus facilitating occurrence of HIV infection cases in advanced stages of immunosuppression. A high level of suspicion of systemic mycoses and concurrent infection by several opportunistic pathogens is required in severely immunocompromised patients.
\end{abstract}

Keywords: Cryptococcosis, Histoplasmosis, Cryptosporidiosis, Human immunodeficiency virus (HIV), Opportunistic infection

\section{Background}

The most frequent systemic mycoses in immunocompromised patients are pneumocystosis, cryptococcosis, histoplasmosis, candidiasis and aspergillosis. Their incidence has been reduced in $20-25 \%$ since the introduction of highly active anti-retroviral therapy (HAART) more than two decades ago [1]. Histoplasmosis and cryptococcosis are major causes of morbimortality in immunocompromised patients due to HIV infection [2], with a global mortality of 37.2 and $81.8 \%$ respectively $[1,3]$. We report the case of a patient with HIV infection with a CD4 T lymphocyte cell (CD4) count of 2 cells $/ \mathrm{mm} 3$, who presented concurrent infection of three opportunistic pathogens: Cryptococcosis, disseminated histoplasmosis and cryptosporidiosis.

\footnotetext{
* Correspondence: deving.arias@gmail.com

${ }^{1}$ Resident of internal medicine, Universidad Tecnológica de Pereira, Pereira, Colombia

${ }^{5}$ Grupo de Investigación de Medicina Interna, Universidad Tecnológica de Pereira, Pereira, Colombia

Full list of author information is available at the end of the article
}

Histoplasma capsulatum and Cryptococcus neoformans are present in soils contaminated with droppings of birds, bats and pigeons [3]. The infection is acquired by inhalation of spores. Histoplasma capsulatum is a dimorphic fungus endemic to North America close to the Ohio and Mississippi River Valleys, Central and South America. The disease develops by initial contact with the fungus or by endogenous reactivation from a previous exposure. In immunocompromised patients it produces a progressive and disseminated disease with multi-organ involvement, mostly extrapulmonary, of the reticuloendothelial system, bone marrow and skin [4]. Cutaneous lesions have several forms: papular, macular, maculopapular or nodular eruption; flat, crusted, acneiform, purple or hemorrhagic lesions; sometimes they are ulcerative and lepromatous-like [3]. Pulmonary involvement can be seen in chest X-ray in the form of diffuse reticulonodular opacities in $70 \%$ of cases [4]. Cryptococcus neoformans var. neoformans is a ubiquitous saprophytic fungus, which causes an invasive infection with preference for the central nervous system in the form of 
meningoencephalitis. Its prevalence was reduced in western countries to less than 10\% [5]. Cryptosporidiosis is caused by the protozoan parasite of the species Cryptosporidium spp. It is a frequent cause of diarrhea in immunocompromised patients; it can cause chronic, transient or acute profuse diarrhea. Subclinical infections are also possible [6].

\section{Case report}

A 32-year-old Colombian male, resident of an urban area, heterosexual without a stable partner. His medical record was notable for transfusion of fresh frozen plasma 4 years ago due to a consumption coagulopathy caused by sepsis secondary to perforated appendicitis. The patient consulted for 6 months of diarrhea with abundant 4 to 5 foamy, foul-smelling stools per day, no blood or mucus were present in feces. It was associated with asthenia, anorexia, and non-productive dry cough, nocturnal diaphoresis, fever and weight loss of $12 \mathrm{Kg}$ (body mass index, BMI, $15.22 \mathrm{Kg}$ / $\mathrm{m} 2$ ). In the last month, he presented a reddish generalized non-confluent maculopapular rash without compromise of palms and soles (Fig. 1). Physical examination showed painless hepatomegaly, without other abnormalities.

A fourth-generation human immunodeficiency virus (HIV) assay was positive, and viral load was $636.000 \mathrm{VIH}-1$ RNA copies/ml, Log10: 5.80, CD4 T lymphocyte cell (CD4) count was 2 cells/mm3. Modified Ziehl-Neelsen stain in feces showed oocysts of Cryptosporidium spp, and a Multiplex Polymerase chain reaction (PCR) FilmArray test in feces identified Cryptosporidium and enteropathogenic Escherichia coli. Esophagogastroduodenoscopy and colonoscopy were performed and did not show macroscopic abnormalities; several biopsies were taken from the third

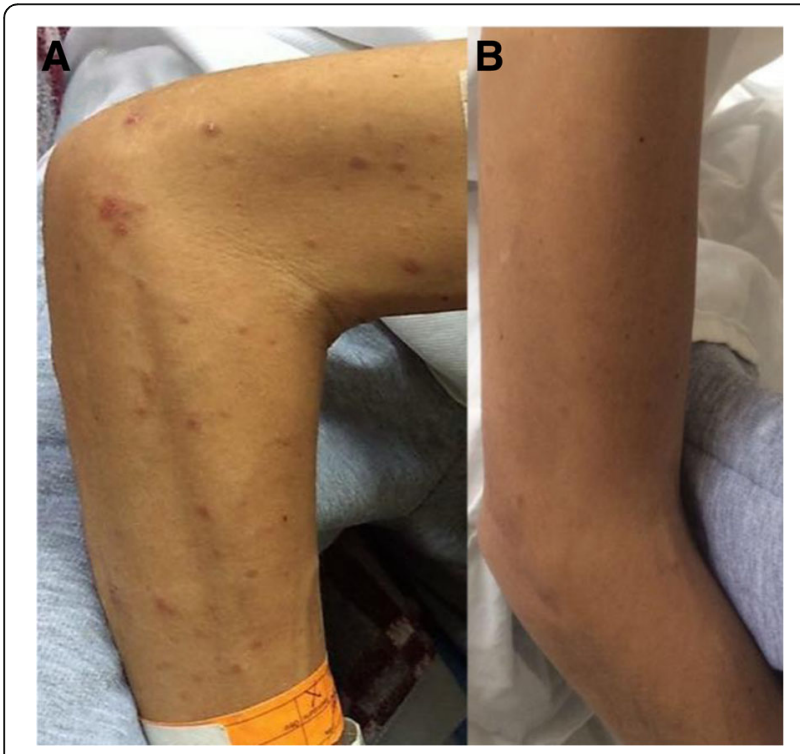

Fig. 1 Skin of the patient's arm before and after antifungal treatment a. Erythematous papules in right upper limb. b. The disappearance of lesions 2 weeks after treatment portion of the duodenum, cecum, transverse and sigmoid colon; they did not reveal any abnormalities either. Serum Cytomegalovirus (CMV) viral load was negative. The patient received treatment with Nitazoxanide $500 \mathrm{mg}$ PO B.I.D for three days with resolution of the diarrhea.

On admission blood cultures were taken. Fungi grew in blood cultures. A preliminary Gram stain exhibited budding yeasts, India ink test was positive for Cryptococcus spp. The blood culture final report confirmed Cryptococcus neoformans. Lumbar puncture was performed to rule out central nervous system involvement. Cerebrospinal fluid tests were taken: cytology, chemistry, routine stains, and Multiplex PCR FilmArray were negative. Induction treatment with amphotericin B at a dose of $1.0 \mathrm{mg} / \mathrm{kg}$ Q.D and fluconazole $800 \mathrm{mg}$ Q.D were given for 2 weeks.

A chest X-ray and a thorax computed tomography (CT) scan showed a random distribution of micro-nodular lesions, with a preference for peripheral areas of the lungs (Fig. 2). Given these findings, we decided to perform a bronchoscopy with optical fiber with findings of lesions compatible with candidiasis in oropharynx and laryngopharynx, without other lesions present in the rest of the study. The fluid extracted from the bronchoalveolar lavage (BAL) was negative for routine stains: $\mathrm{KOH}$ test, Gram and Ziehl Neelsen. Fungi and Mycobacteria cultures and a GeneXpert assay for Mycobacterium tuberculosis (MTB) were negative. Cytological studies of the fluid did not exhibit cellular atypia.

Other laboratory tests showed hyperferritinemia (patient value $=1000 \mathrm{ng} / \mathrm{mL}$, reference value $23-336 \mathrm{ng} /$ $\mathrm{mL}$ ) and mild elevation of alkaline phosphatase (patient value $=152 \mathrm{U} / \mathrm{L}$, reference value $=38-126 \mathrm{U} / \mathrm{L}$ ) which raised suspicion for histoplasmosis due to the findings of hepatomegaly, skin rash and the random micronodular compromise seen in the chest images. A galactomannan antigen test for Histoplasma capsulatum was performed in urine (with enzyme immunoassay (EIA), Immuno Mycologics IMMY) and was positive with $137 \mathrm{ng} / \mathrm{mL}$ (reference value $<0.5 \mathrm{ng} / \mathrm{ml}$ ), which confirmed the diagnosis of disseminated histoplasmosis. Due to these findings, fluconazole was stopped and maintenance therapy was initiated with Itraconazole $200 \mathrm{mg}$ T.I.D for three days and then B.I.D at least for 1 year.

The patient had a satisfactory outcome, with resolution of his diarrhea, disappearance of his rash by the end of the induction phase, and the respiratory symptoms also improved. Patient was discharged with the indication to start HAART with Tenofovir/Emtricitabine $300 / 200 \mathrm{mg}$ Q.D and Raltegravir $400 \mathrm{mg}$ B.I.D four weeks after induction therapy.

\section{Discussion}

Histoplasmosis and cryptococcosis are two of the fungal diseases with higher prevalence in immunocompromised 


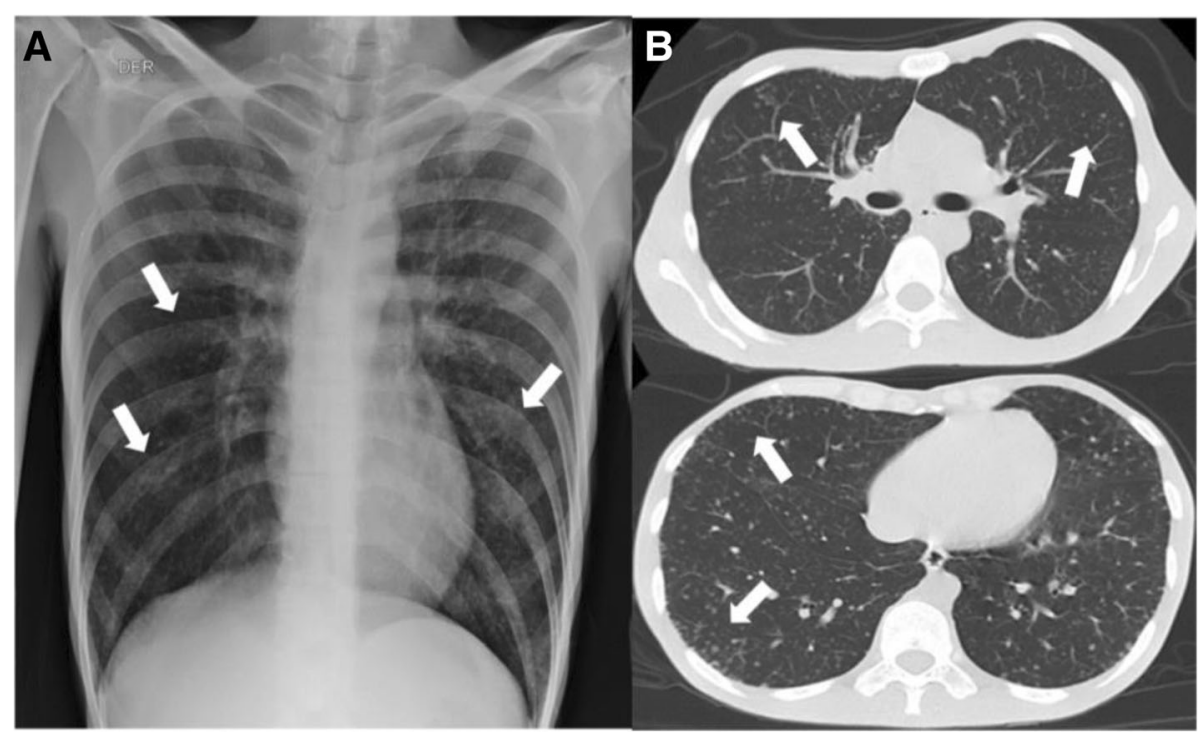

Fig. 2 Patient images showing random distribution of micro-nodular opacities. a. Chest X-ray. b. Thorax CT scan

patients, especially in those with advanced HIV infection and CD4 T lymphocyte cell (CD4) counts lower than 150 and 100 cells/mm3, respectively [7]. Clinical features of both mycoses are similar, presenting with fever, asthenia, adynamia, weight loss, cough, dyspnea, expectoration, diarrhea, lymphadenopathy, hepatomegaly and the beginning of symptoms is insidious [2, 8]. Cutaneous lesions are more frequent in histoplasmosis and the involvement of central nervous system is more frequent in cryptococcosis [3, 4]. Both diseases are causes of morbimortality separately. Report of coinfection of histoplasmosis and cryptococcosis is rare; therefore, a higher mortality can be expected.

In the case presented, we confirmed the diagnosis of two opportunistic infections (Cryptosporidiosis and Cryptococcosis) and we considered the probable diagnosis of histoplasmosis based on the results of the urinary antigen for histoplasmosis and clinical plausibility, mainly for cutaneous manifestations and the random micronodular compromise seen in chest images. In this patient the bronchoalveolar fluid studies were negative and unfortunately no biopsies were taken. There are cross reactions of the urinary antigen test of Histoplasma capsulatum var. capsulatum with other infections such as Paracoccidioides brasiliensis, Blastomyces dermatitidis, Coccidioides immitis, and Penicillium marneffei. These microorganisms should be considered in cases when there are doubts about co-infection with endemic mycoses. [9]. Although it is rare that three opportunistic infections coincide in the same person, our patient had a severe state of immunosuppression and had cutaneous manifestations, which together with the fact that histoplasmosis is endemic in our region, makes a clinically strong plausibility for this infection. We support the diagnosis of Histoplasmosis by the presence of the urinary antigen test of Histoplasma capsulatum var. capsulatum that has high sensitivity and specificity and apparently no cross-reaction with cryptococcosis as seen in an antigenuria validation study to diagnose disseminated histoplasmosis in Latin American countries: cross-reactivity was found in three cases of Paracoccidioidomycosis and none in 12 cases of cryptococcosis. [10]. For these reasons, we considered that histoplasmosis was present and therefore, we started antimicrobial treatment with itraconazole as we have already described although we could not have a visual confirmation and considering that cultures have a low diagnostic yield for histoplasmosis.

A Review in PUBMED from 1970 to August/2018 was performed, and 12 cases of patients with coinfection by Histoplasma capsulatum and Cryptococcus spp were found. Other authors performed similar reviews $[8,11]$. In Colombia, in a series of 11 cases of Arango et al. [3] a case of coinfection by histoplasmosis and cryptococcosis was reported. So far, we have no information of other cases reported in Colombia. We added both cases to the list of cases reported (Table 1).

There are still regions where HIV detection programs are deficient and facilitate the occurrence of HIV infection cases in advanced stages of immunosuppression. In these patients there must be a high level of suspicion regarding existence of multiple opportunistic infections. We consider that these cases are complex and require an exhaustive search and an adequate correlation with the clinical findings, with the limitation that clinical manifestations can be vague and nonspecific. Cross reactions of non-invasive tests are a concern because, in the case of 
Table 1 Reported cases of histoplasmosis and cryptococcosis coinfection

\begin{tabular}{|c|c|c|c|c|c|}
\hline & Sex, age, country & Underlying pathology & Treatment & Outcome & Reference \\
\hline 1 & $\begin{array}{l}\text { Male, 38-years old, } \\
\text { United States of America }\end{array}$ & AIDS & Amphotericin B & Death & [12] \\
\hline 2 & $\begin{array}{l}\text { Male, 27-years old, } \\
\text { United States of America }\end{array}$ & AIDS & $\begin{array}{l}\text { Flucytosine, Fluconazole, trimethoprim/ } \\
\text { sulfamethoxazole (TMP/SMX) }\end{array}$ & Alive & [13] \\
\hline 3 & Male, 76-years old, Puerto Rico & $\begin{array}{l}\text { Diabetes Mellitus, autoimmune } \\
\text { thrombocytopenia } \\
\text { Corticosteroids }\end{array}$ & Amphotericin B & Alive & [14] \\
\hline 4 & Female, 23-years old, France & AIDS & Amphotericin B, Fluconazole & Alive & [2] \\
\hline 5 & Male, 46-years old, Ecuador & AIDS & Amphotericin B & Death & [15] \\
\hline 6 & Female, 20-years old, Brazil & AIDS & Amphotericin B, Flucytosine, Fluconazole & Alive & [8] \\
\hline 7 & Male, 32-years old, India & AIDS & Amphotericin B, Fluconazole & Alive & [16] \\
\hline 8 & Male, 22-years old, Paraguay & AIDS & Amphotericin B, Fluconazole & Alive & [17] \\
\hline 9 & Female, 29-years old, Brazil & Immunocompetent & Without treatment & Alive & [18] \\
\hline 10 & Male, 27-years old, Ecuador & AIDS & Amphotericin B, Itraconazole & Alive & [19] \\
\hline 11 & Male, 69-years old, Brazil & COPD, T2DM & Amphotericin B, Fluconazole & Death & [11] \\
\hline 12 & Male, 33-years old, Brazil & AIDS & Amphotericin B, Fluconazole & Alive & [20] \\
\hline 13 & $\begin{array}{l}1 \text { patient of a case series, } \\
\text { Colombia }\end{array}$ & AIDS & Without information & Without information & [3] \\
\hline 14 & Male, 32-years old, Colombia & AIDS & Amphotericin B, Fluconazole, Itraconazole & Alive & Present case \\
\hline
\end{tabular}

AIDS acquired immune deficiency syndrome, COPD Chronic Obstructive Pulmonary Disease T2DM Type 2 Diabetes Mellitus

mycosis many other fungi could be responsible in cross-reactions with the urinary antigen test for histoplasmosis due to the production of galactomannan. But in Latin America this should be considered especially in endemic mycoses such as paracoccidioidomycosis causing cross-reactions with the histoplasmosis antigen test. This essay requires a careful interpretation in these scenarios, but clearly it is an inexpensive, effective and non-invasive tool to reach the diagnosis of histoplasmosis.

\footnotetext{
Abbreviations

AIDS: acquired immune deficiency syndrome; BAL: bronchoalveolar lavage; BID: "bis in die", which means, in Latin, twice a day; BMI: body mass index; CMV: Cytomegalovirus; COPD: Chronic Obstructive Pulmonary Disease; CT: computed tomography; HAART: highly active anti-retroviral therapy; MTB: Mycobacterium tuberculosis; PCR: Polymerase chain reaction; QD: "quaque die", which means, in Latin, once a day; T2DM: Type 2 Diabetes Mellitus; TID: "ter in die" which means, in Latin, three times a day:; TMP/ SMX: Trimethoprim/sulfamethoxazole.
}

\section{Acknowledgments}

To the Hospital Universitario San Jorge de Pereira, Colombia, where the diagnosis and treatment of the patient was made.

\section{Author contribution}

DAR and JAA were the main responsible for the writing of the full article and most of the ideas presented. JAR and NA participated in the review of the literature and in some ideas of the writing of the introduction and discussion. All the authors were involved in the diagnosis and treatment of the patient All authors read and approved the final manuscript.

\section{Funding}

The mentioned authors are not currently receiving and have not received any financial support for the development of the manuscript mentioned above. This research did not receive any specific grant from funding agencies in the public, commercial, or not-for-profit sectors.

\section{Availability of data and materials}

Data sharing not applicable to this article as no datasets were generated or analyzed during the current study.

\section{Ethics approval and consent to participate}

This article is of the case report type. We obtained informed consent from the patient to make the case report in accordance with the ethical responsibilities of the authors.

\section{Consent for publication}

We have obtained consent to publish from the participant to report individual patient data. Consent to publish was given in written format.

\section{Competing interests}

The authors declare that they have no competing interest. None of the authors have financial and non-financial conflicts of interest.

\section{Publisher's Note}

Springer Nature remains neutral with regard to jurisdictional claims in published maps and institutional affiliations.

\section{Author details}

${ }^{1}$ Resident of internal medicine, Universidad Tecnológica de Pereira, Pereira, Colombia. Internal Medicine specialist at the Hospital Universitario San Jorge, and associate professor at the Universidad Tecnológica de Pereira, Pereira, Colombia. ${ }^{3}$ Physician. Universidad Tecnológica de Pereira, Pereira, Colombia. ${ }^{4}$ Medical student, Universidad Tecnológica de Pereira, Pereira, Colombia. ${ }^{5}$ Grupo de Investigación de Medicina Interna, Universidad Tecnológica de Pereira, Pereira, Colombia.

Received: 5 October 2018 Accepted: 14 December 2018

Published online: 27 December 2018

\section{References}

1. de Oliveira RB, Atobe JH, Souza SA, de Castro Lima Santos DW. Epidemiology of invasive fungal infections in patients with acquired immunodeficiency syndrome at a reference hospital for infectious diseases in Brazil. Mycopathologia 2014 Aug;178(1-2):71-78. PubMed PMID: 24952013. Epub 2014/06/22. eng 
2. Ferry T, Ponceau B, Gaultier JB, Piens MA, Biron F, Picot S, et al. Disseminated cryptococcosis and histoplasmosis co-infection in a HIVinfected woman in France. The J Infect 2005 Oct;51(3):e173-e176. PubMed PMID: 16230201. Epub 2005/10/19. eng.

3. Myrtha Arango LEC, Catalina de Bed. Histoplasmosis y criptococosis diseminada en pacientes con el síndrome de inmunodeficiencia adquirida (SIDA) Acta Médica Colombiana. 1990;15 (2).

4. Ángela M, Tobón AM. Luisa Orozco, Carlos Restrepo, Diego Molina, Catalina de Bedout, Ángela Restrepo. Histoplasmosis diseminada progresiva en una cohorte de pacientes coinfectados con el VIH. Acta Médica Colombiana. 2011;36(2):63-7.

5. Dromer F, Mathoulin-Pelissier S, Fontanet A, Ronin O, Dupont B, Lortholary O. Epidemiology of HIV-associated cryptococcosis in France (1985-2001): comparison of the pre- and post-HAART eras. AIDS (London, England). 2004 Feb 20;18(3):555-562. PubMed PMID: 15090810. Epub 2004/04/20. eng.

6. Chen X-M, Keithly JS, Paya CV, LaRusso NF. Cryptosporidiosis. N Engl J Med 2002;346(22):1723-1731. PubMed PMID: 12037153.

7. Adolescents PoOliH-IAa. Guidelines for the prevention and treatment of opportunistic infections in HIV-infected adults and adolescents: recommendations from the Centers for Disease Control and Prevention, the National Institutes of Health, and the HIV Medicine Association of the Infectious Diseases Society of America. http://aidsinfonihgov/contentfiles/ Ivguidelines/adult_oipdf.

8. Aronis ML, dos Santos RP, Goldani LZ. Disseminated Histoplasma capsulatum and Cryptococcus neoformans co-infection in patients with AIDS. Mycopathologia 2011 Sep;172(3):233-236. PubMed PMID: 21472390. Epub 2011/04/08. eng.

9. Wheat J, Wheat H, Connolly P, Kleiman M, Supparatpinyo K, Nelson K, et al. Cross-reactivity in Histoplasma capsulatum variety capsulatum antigen assays of urine samples from patients with endemic mycoses. Clin Infect Dis 1997;24(6):1169-1171. PubMed PMID: 9195077. Epub 1997/06/01. eng.

10. Caceres DH, Samayoa BE, Medina NG, Tobon AM, Guzman BJ, Mercado D, et al. Multicenter validation of commercial Antigenuria reagents to diagnose progressive disseminated histoplasmosis in people living with HIV/AIDS in two Latin American countries. J Clin Microbiol 2018 Jun;56(6). PubMed PMID: 29563205. Pubmed Central PMCID: 5971531.

11. Nunes JO, Pillon KR, Bizerra PL, Paniago AM, Mendes RP, Chang MR. The simultaneous occurrence of histoplasmosis and Cryptococcal Fungemia: a case report and review of the literature. Mycopathologia 2016 Dec;181(1112):891-897. PubMed PMID: 27423433. Epub 2016/07/18. eng.

12. Holmes GP, Noble RC. Three fungal infections in an AIDS patient. J Kentucky Med Assoc 1986;84(5):225-226. PubMed PMID: 3722991. Epub 1986/05/01. eng.

13. Myers SA, Kamino H. Cutaneous cryptococcosis and histoplasmosis coinfection in a patient with AIDS. J Am Acad Dermatol 1996;34(5 Pt 2): 898-900. PubMed PMID: 8621824. Epub 1996/05/01. eng.

14. Ramirez-Ortiz R, Rodriguez J, Soto Z, Rivas M, Rodriguez-Cintron W. Synchronous pulmonary cryptococcosis and histoplasmosis. South Med J 1997;90(7):729-732. PubMed PMID: 9225897. Epub 1997/07/01. eng.

15. Swaminathan S, Imrit K, Green J, Das K. Concomitant disseminated histoplasmosis and cryptococcosis in a person with AIDS. AIDS Read 2006; 16(11):602-606. PubMed PMID: 17152648. Epub 2006/12/13. eng.

16. Ghosh A, Tilak R, Bhushan R, Dhameja N, Chakravarty J. Lymphnodal coinfection of Cryptococcus and Histoplasma in a HIV-infected patient and review of published Reports. Mycopathologia 2015;180(1-2):105-110. PubMed PMID: 25743378. Epub 2015/03/07. eng.

17. Corti M, Boschi A, Villafañe MF, Messina F, Negroni R, Arechavala A, et al. Criptococosis E Histoplasmosis Diseminadas Y SimultÁneas Como Primera Manifestación De Sida. Revista de Patologia Tropical. 2015;43(4).

18. Dantas KC, de Freitas RS, Garcia RSP, da Silva MV, Muricy ECM, Kohara VS, et al. Importance of the association of molecular and immunological diagnosis in immunocompetent patient with Histoplasma capsulatum and Cryptoccocus neoformans infection: a case report. Journal of Venomous Animals and Toxins including Tropical Diseases. 2014 August 26;20(1):36

19. Gandhi V, Rali P. Cryptococcal Pneumonia And Disseminated Histoplasma Co-Infection In A Newly Diagnosed HIV Patient. A53 INFECTIOUS DISEASES CASE REPORTS II. p. A1770-A.

20. Almeida-Silva F, Damasceno LS, Serna MJ, Valero C, Quintella LP, AlmeidaPaes $R$, et al. Multiple opportunistic fungal infections in an individual with severe HIV disease: a case report. Rev Iberoam Micol 2016 Apr-Jun;33(2): 118-121. PubMed PMID: 26896884. Epub 2016/02/22. eng.

\section{Ready to submit your research? Choose BMC and benefit from:}

- fast, convenient online submission

- thorough peer review by experienced researchers in your field

- rapid publication on acceptance

- support for research data, including large and complex data types

- gold Open Access which fosters wider collaboration and increased citations

- maximum visibility for your research: over $100 \mathrm{M}$ website views per year

At BMC, research is always in progress.

Learn more biomedcentral.com/submissions 